06

\title{
Особенности влияния облучения ионами железа на развитие гелиевых, водородных и дейтериевых блистеров в кремнии
}

\author{
(C) В.Ф. Реутов, ${ }^{1}$ С.Н. Дмитриев, ${ }^{1}$ А.С. Сохацкий, ${ }^{1}$ А.Г. Залужный ${ }^{2}$ \\ ${ }^{1}$ Объединенный институт ядерных исследований им. Г.Н. Флерова, \\ 141980 Дубна, Московская область, Россия \\ ${ }^{2}$ Национальный исследовательский ядерный университет „МИФИ,“ \\ 115409 Москва, Россия \\ e-mail: reutov@jinr.ru
}

(Поступило в Редакцию 10 марта 2016 г.)

Исследовалось влияние облучения ионами железа на эволюцию газовой пористости в монокристаллах кремния. Газовая пористость создавалась имплантацией при комнатной температуре ионов водорода, дейтерия и гелия с энергиями 17, 12.5 и $20 \mathrm{keV}$ соответственно одинаковыми дозами $1 \times 10^{17} \mathrm{~cm}^{-2}$ при комнатной температуре. При таких энергиях бомбардирующих ионов профили ионного легирования формировались на одном расстоянии от облучаемой поверхности образца. После чего образцы облучались при комнатной температуре ионами железа $\mathrm{Fe}^{10+} \mathrm{c}$ энергией $150 \mathrm{keV}$ дозой $5.9 \cdot 10^{14} \mathrm{~cm}^{-2}$. Затем на воздухе проводились получасовые изохронные отжиги с интервалом $50^{\circ} \mathrm{C}$ в диапазоне температур от 250 до $900^{\circ} \mathrm{C}$. Исследование образцов проводилось на оптическом и электронном микроскопах. Был обнаружен крайне сильный синергетический эффект влияния последовательного облучения ионами газов и ионами железа образцов монокристаллического кремния при комнатной температуре на зарождение и рост газовой пористости в процессе послерадиационного отжига. Так, было показано, что аморфный слой в кремнии, сформированный дополнительным облучением ионами железа, стимулирует развитие гелиевых блистеров, незначительно уменьшает развитие водородных блистеров и полностью подавляет развитие дейтериевых блистеров. Полученные результаты не позволяют в настоящий момент сформулировать скольконибудь адекватного объяснения причин такого различия, необходимы дополнительные целенаправленные эксперименты.

DOI: 10.21883/JTF.2017.02.44129.1801

\section{Введение}

Образование и поведение пор в твердых телах активно исследуются более 50 лет. В частности, это обусловлено их катастрофическим влиянием на деградацию свойств материалов в процессе облучения в ядерных и термоядерных реакторах. Так, радиационно-индуцированные газонаполненные поры (bubbles) и пустые полости (voids) являются причинами катастрофических изменений механических и размерных характеристик конструкционных и делящихся материалов.

В ряде других материалов, например для электронной промышленности, наоборот, пористость используется с целью улучшения их физико-химических и механических свойств. Так, открытый в 50-е годы электрохимический способ формирования пористой структуры в кремнии, который является основным материалом современной электроники, стимулировал ее интенсивное комплексное исследование, на основании которого были предложены новые области применения пористых кремниевых слоев.

В настоящее время на основе пористого кремния (ПК) [1-3] активно разрабатываются функциональные элементы сверхбольших интегральных схем, устройства ультразвуковой электроники, солнечные элементы, волноводы, датчики влажности и состава газов, биосенсоры, фотонные кристаллы, интегральные конденсаторы и т.д. Однако серьезным препятствием для понимания общей картины изменения электрических свойств ПК, изготовленного электрохимическим способом, являлось многообразие морфологических особенностей материала и их зависимость от технологических параметров формирования пористой структуры. В этой связи перспективы применения слоев ПК в приборах и устройствах электроники вызвали необходимость изучения альтернативных способов их формирования и методов управления их морфологическими и количественными параметрами. Одним из перспективных методов формирования контролируемых пористых слоев явился ионноимплантационный способ, связанный с использованием облучения материала ускоренными ионами газов, в частности ионами водорода, дейтерия и гелия.

В 60-х годах были получены первые результаты ионно-имплантационного формирования газовой пористости в кремнии [4]. В 80-х годах в работе [5] впервые был предложен радиационно-газовый способ безотходного получения тонких плоскопараллельных монокристаллических пластин кремния, на базе которого в 90-х годах был развит промышленный способ получения структур типа „кремний на изоляторе“ [6,7], а в 2000-х годах было развито промышленное безотходное производство тонких пластин солнечного кремния [8]. В 90-х годах после обнаружения эффективной геттерирующей способности пористой структуры, сформированной ионноимплантационным способом [9,10], нашла успешное раз- 
витие методология целенаправленной очистки от примесей переходных металлов заданных микрообластей в полупроводниковых объектах.

Получение максимально возможных заданных эффектов от пористой структуры при решении проблем в вышеперечисленных направлениях требует целенаправленных комплексных исследований реализации специфических условий формирования, развития и стабильности пористой структуры, поскольку для каждого из вышеперечисленных направлений использования радиационноиндуцированной пористости требуется своя морфология, размерное распределение, термическая и радиационная стойкости.

Так, например, для решения проблемы безотходного скалывания монокристаллических пластин полупроводников субмикронных толщин необходимо реализовать условие распространения трещины в области скалывания без формирования блистерной структуры, как это реализуется, например, при скалывании толстых пластин [5,8]. Одним из способов решения этой проблемы может быть радиационно-индуцированное упрочнение скалываемого слоя. В рамках начального этапа решения данной проблемы было исследовано влияние на развитие гелиевых, водородных и дейтериевых блистеров дополнительного радиационно-индуцированного упрочнения скалываемого слоя, например путем его легирования облучением ионами железа. Было обнаружено нетривиальное проявление противоположной роли радиационного повреждения ионами железа в развитии гелиевых, водородных и дейтериевых блистеров. Так, сформированный облучением ионами железа аморфный слой в образцах кремния, предварительно легированных ионами гелия, водорода и дейтерия, проявил себя в эффективном стимулировании процесса развития гелиевых блистеров, и наоборот, в эффекте полного подавления процесса формирования дейтериевых блистеров, не оказывая существенного влияния на развитие водородных блистеров.

\section{Экспериментальная часть}

В качестве объектов для исследований были взяты три образца монокристаллического кремния марки КЭФ-4.5 (100), которые были облучены в ЭЦР источнике (ОИЯИ-ЛЯР, Дубна) при комнатной температуре ионами водорода, дейтерия и гелия с энергиями соответственно 17, 12.5 и $20 \mathrm{keV}$ одинаковыми дозами $1 \cdot 10^{17} \mathrm{~cm}^{-2}$. Выбор величины энергии бомбардирующих частиц исходил из необходимости формирования подобных энергетических профилей ионного легирования на одной глубине в образцах, поскольку известно [11], что размер блистеров зависит от проективного пробега бомбардирующих ионов. Проективный пробег ионов водорода, дейтерия и гелия данных энергий в кремнии составляет около $0.2 \mu \mathrm{m}$.

Последующее единовременное облучение данных образцов проводилось на том же ЭЦР источнике при комнатной температуре ионами $\mathrm{Fe}^{10+}$ с энергией $150 \mathrm{keV}$ дозой $5.9 \cdot 10^{14} \mathrm{~cm}^{-2}$. Облучение проводилось через поглощающую маску в виде сетки, что позволяет в одних условиях облучения и послерадиационных отжигов одновременно наблюдать за структурными изменениями в облученных и необлученных участках одного образца.

При облучении ионами $\mathrm{Fe}^{10+}$ с энергией $150 \mathrm{keV}$ их проективный пробег в кремнии составляет около $0.15 \mu \mathrm{m}$, поэтому концентрационные профили радиационных дефектов и внедренных атомов железа смещены к бомбардируемой поверхности относительно аналогичных профилей, сформированных при облучении ионами газов.

Именно это обстоятельство использовалось как для выделения определяющего вклада в блистерообразование упрочненной облучением ионами железа приповерхностной области кремния, так и для сравнительной оценки геттерных возможностей поверхности газовых пор при частичном наложении концентрационного профиля атомов железа на концентрационные профили атомов различных газов.

Послерадиационные получасовые изохронные отжиги с интервалом $50^{\circ} \mathrm{C}$ в диапазоне температур от 250 до $900^{\circ} \mathrm{C}$ проводились на воздухе.

Регистрация блистерообразования в исследуемых образцах кремния проводилась в оптическом микроскопе, используя дифференциально-интерференционный метод Номарского.

Электронно-микроскопические исследования образцов в геометрии „сross section“ проводились на JEM 2000 с использованием FIB-установки.

Прежде всего отметим, что исследования в оптическом микроскопе поверхности всех образцов кремния как после имплантации ионам водорода, дейтерия и гелия, так и после последующего их облучения ионами железа не показали сколько-нибудь заметных структурных изменений.

\section{Результаты}

\section{Гелиевые блистеры}

Изохронные получасовые отжиги с интервалом $50^{\circ} \mathrm{C}$ в диапазоне температур от 250 до $450^{\circ} \mathrm{C}$ не показали сколько-нибудь заметных структурных изменений в областях образца кремния как легированных только атомами гелия, так и дополнительно облученных ионами железа. Взрывной характер изменения структуры в виде появления на поверхности образца в областях, облученных ионами $\mathrm{Fe}$, блистеров и флэкингов проявился после отжига при $500^{\circ} \mathrm{C}$ (рис. 1).

Следует отметить характерные особенности наблюдаемой блистерно-флэкинговой структуры. Во-первых, размер блистеров практически в 2 раза больше размера флэкингов. Во-вторых, блистеры и флэкинги не статистически распределены по поверхности образца, а группируются в отдельных областях. В-третьих, плотность флэкингов в 3 раза выше плотности блистеров, хотя 


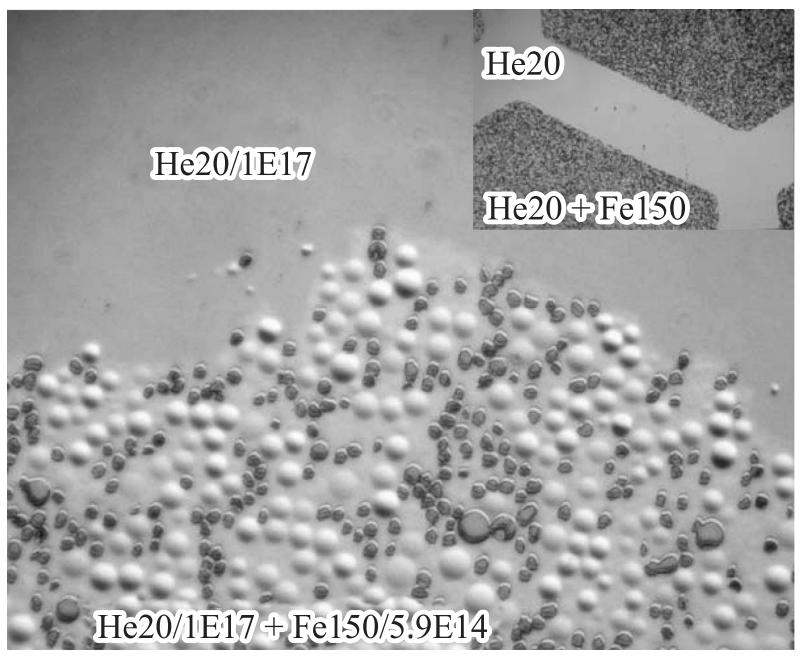

Рис. 1. Структура участков образца, облученных только ионами гелия $\left(\mathrm{He} 20, \mathrm{keV} / 1 \cdot 10^{17} \mathrm{~cm}^{-1}\right.$ — чистое поле) и последовательно облученных ионами гелия и железа $\left(\mathrm{He} 20 \mathrm{keV} / 1 \cdot 10^{17} \mathrm{~cm}^{-2}+\mathrm{Fe} 150 \mathrm{keV} / 5.9 \cdot 10^{14} \mathrm{~cm}^{-2}\right.$ - поле с блистерами и флэкингами), после получасового отжига при $500^{\circ} \mathrm{C}$. На вставке - облученная поверхность образца при малом увеличении.

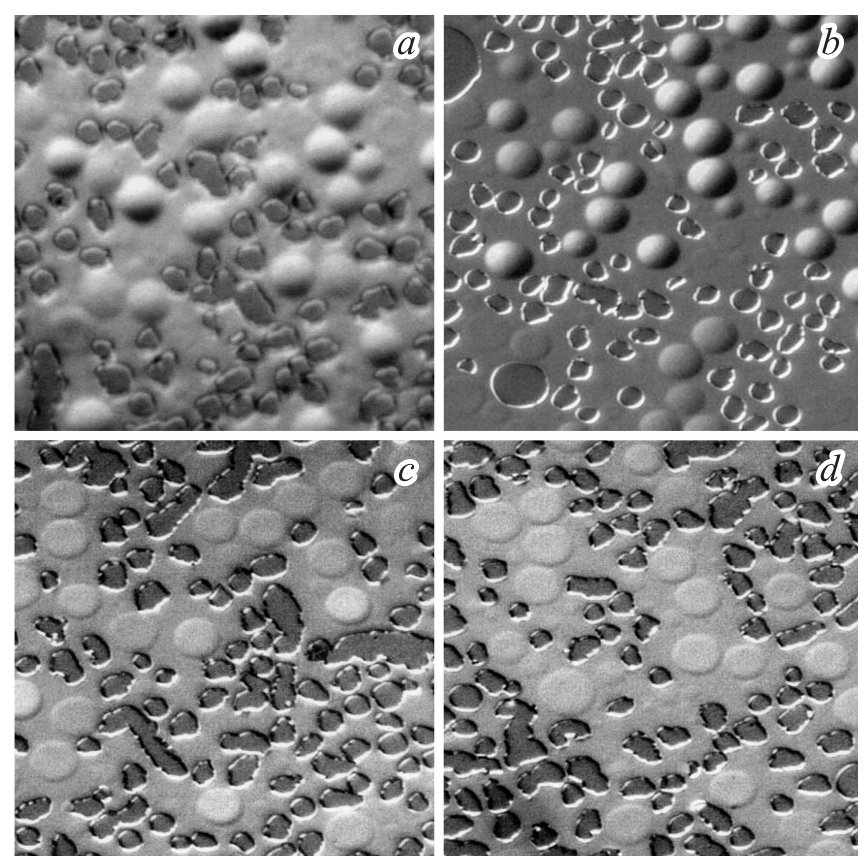

Рис. 2. Изменение профиля поверхности блистеров в области кремния, облученной ионами $\mathrm{He}$ и $\mathrm{Fe}$, в результате получасовых изохронных отжигов при температурах $500(a), 600(b)$, $700(c)$ и $900^{\circ} \mathrm{C}(d)$.

их относительные площади практически одинаковые и в сумме составляют около $45 \%$.

Дальнейшие отжиги вплоть до $900^{\circ} \mathrm{C}$, во-первых, не вызвали появления каких-либо структурных образований в областях, легированных только гелием, и, во-вторых, практически не изменили как размерные параметры блистеров и флэкингов, так и характер их пространственного распределения в областях, дополнительно облученных ионами Fе. Однако особо отметим изменения в морфологии блистеров (рис. 2). Так, если вплоть до $600^{\circ} \mathrm{C}$ поверхность большей части блистеров имела полусферическую форму, то после $700^{\circ} \mathrm{C}$ поверхность всех блистеров приобрела плоскую форму. Подобное изменение дает основание предположить, что газовое давление, сдерживающее полусферическую форму крышек блистеров при данной температуре, не увеличилось, a, наоборот, уменьшилось за счет десорбции из них гелия, поэтому и не реализовались условия отрыва крышек блистеров, т.е. образования флэкингов. Более того, такое изменение от полусферической до плоской форм блистеров указывает на упругую деформацию стенок блистеров.

ПЭМ исследования в геометрии „сcoss-section“ проводились на образцах, приготовленных по FIB-способу. При всех своих достоинствах данная методика имеет некоторые ограничения, прежде всего как в площади (размере) объекта исследования, так и трудности изготовления объекта с блистерной структурой. В этой связи приводимые результаты характеризуют только проявление структурных изменений непосредственно после облучения только ионами Не, а также ионами Не и последующего облучения ионами $\mathrm{Fe}$.

На рис. 3 приведены электронно-микроскопические фотографии структурных изменений в образцах кремния непосредственно после облучения только ионами Не $(E=20 \mathrm{keV})$ дозой $1 \cdot 10^{17} \mathrm{~cm}^{-2}$, а также после облучения ионами $\mathrm{He}(E=20 \mathrm{keV})$ дозой $1 \cdot 10^{17} \mathrm{~cm}^{-2}$ и последующего облучения ионами $\mathrm{Fe}(E=150 \mathrm{keV})$ дозой $5.9 \cdot 10^{14} \mathrm{~cm}^{-2}$. При этом для удобства анализа приведенных изображений особенностей структурных изменений они сопряжены с расчетными энергетическими профилями концентраций радиационных дефектов и примесных атомов гелия и железа.

Как видно из рис. 3, $a$ (вставка электронограммы), после облучения ионами гелия имеет место частичная аморфизация радиационно-поврежденного приповерхностного слоя кремния и формирования в нем гелиевых нанопор. Из-за наличия высокой концентрации скоплений радиационных дефектов контраст изображения гелиевых нанопор ослаблен. Тем не менее имеет место характерное немонотонное изменение как концентрации, так и размера нанопор, т. е. соответствующее их увеличение к центру слоя легированного атомами гелия.

В образце, дополнительно облученном ионами $\mathrm{Fe}$, произошла полная аморфизация легированного гелием слоя (рис. 3, $b$, вставка электронограммы), на фоне которого стало проявляться более четкое изображение гелиевых нанопор. Особо отметим, что, несмотря на то что концентрационный профиль имплантированных атомов железа наложен практически на половину концентрационного профиля атомов гелия, тем не менее отсутствуют какие-либо изменения в морфологии и пространственном распределении гелиевых нанопор как 


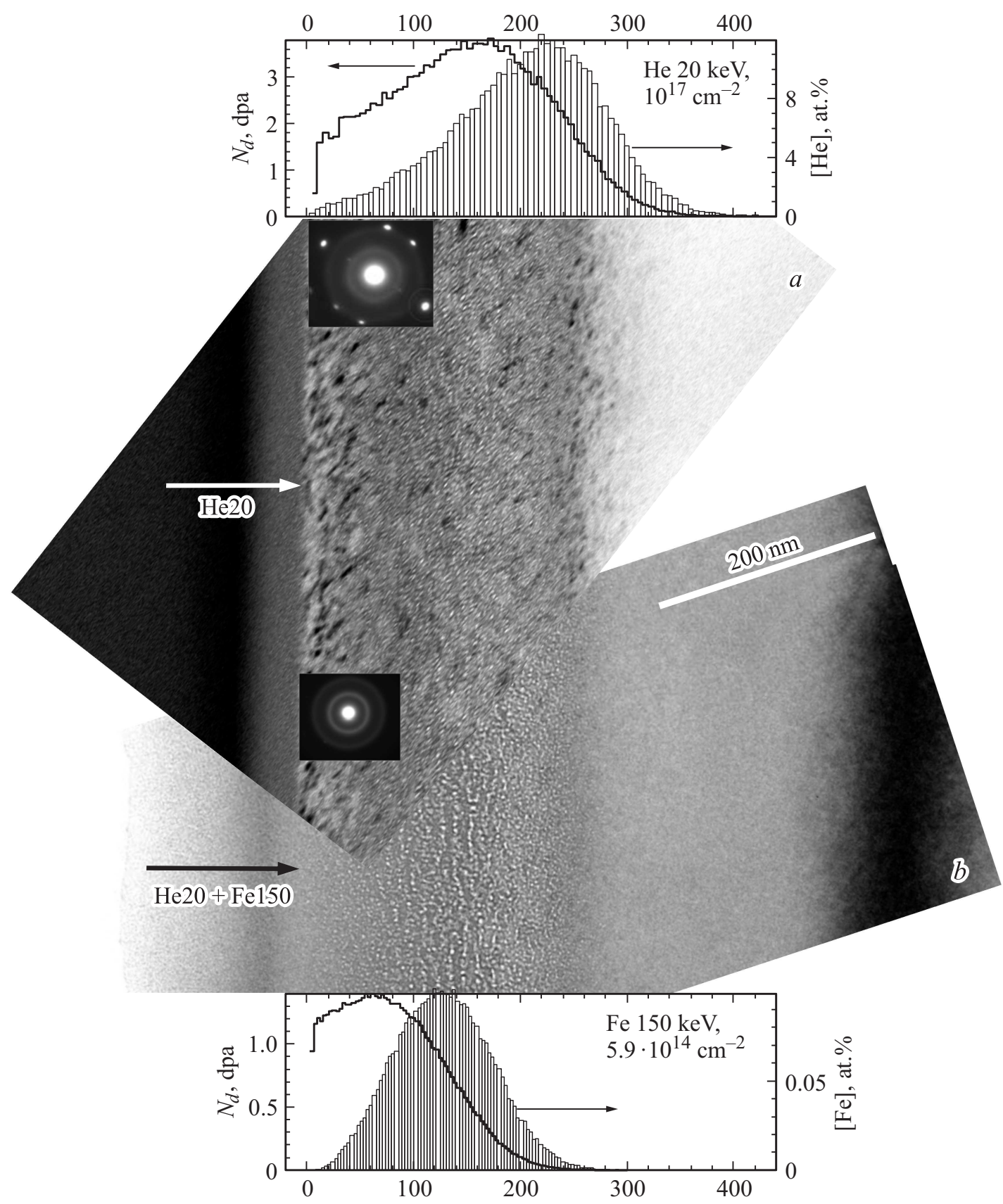

Рис. 3. ПЭМ изображение в геометрии „сross-section“ структурных изменений в кремнии вдоль пробега ионов Не с $E=20 \mathrm{keV}(a)$ и последовательного облучения ионами Не с $E=20 \mathrm{keV}$ и ионами Fe с $E=150 \mathrm{keV}(b)$. На вставках приведены электронограммы структурного состояния данного участка радиационно поврежденного слоя кремния.

от дополнительной аморфизациии ионами $\mathrm{Fe}$, так и от присутствия примесных атомов железа. Это, повидимому, свидетельствует об отсутствии в процессе низкотемпературного облучения ионами железа геттерирования гелиевыми порами примесных атомов железа.

Итак, исходная позиция структурного состояния образца кремния, совместно облученного ионами гелия и железа, перед послерадиационными изохронными отжигами - это гелиевые нанопоры в аморфной матрице кремния в присутствии твердого раствора атомов железа.
Следует предположить, что именно такое сложное состояние кремния, последовательно облученного ионами гелия и железа, и определяет наблюдаемый необычный характер стимулированного развития блистернофлэкинговой структуры в зависимости от температуры послерадиационного отжига.

Таким образом:

- облучение ионами железа способствует стимулированию термических процессов одновременного формирования и роста гелиевых блистеров и флэкингов. При этом различный размер блистеров и флэкингов 
предполагает их образование на различных глубинах в образце кремния, а также различное состояние материалов крышек блистеров, способствующее как хрупкому их скалыванию (образование флэкингов), так и упругой деформации в полусферичных блистерах;

- групповое распределение флэкингов и блистеров по микрообластям образца предполагает квазикристаллическое состояние аморфного кремния. Предполагается, что в квазикристаллических областях формируются условия для образования полусферических блистеров, в аморфных областях - флэкингов;

- изменение морфологии блистеров от полусферических до плоских форм при температуре более $600^{\circ} \mathrm{C}$ предполагает, во-первых, термодесорбцию гелия из блистеров и, во-вторых, наличие упруго-деформационного состояния материала их крышек.

\section{Водородные блистеры}

Изохронные получасовые отжиги через интервал $50^{\circ} \mathrm{C}$ в диапазоне температур от 250 до $350^{\circ} \mathrm{C}$ не показали сколько-нибудь заметных структурных изменений в областях образца кремния как легированных только атомами водорода, так и дополнительно облученных ионами железа. Изменения структуры в данных областях в виде появления на поверхности образца водородных блистеров проявились после отжига при $400^{\circ} \mathrm{C}$ (рис. $4, a)$.

Особо отметим, что характерной отличительной особенностью блистерной структуры в данных областях являются различный контраст и форма в изображении блистеров. Так, в областях, облученных только ионами водорода, блистеры имеют неправильные геометрические формы со слабым контрастом их изображения.

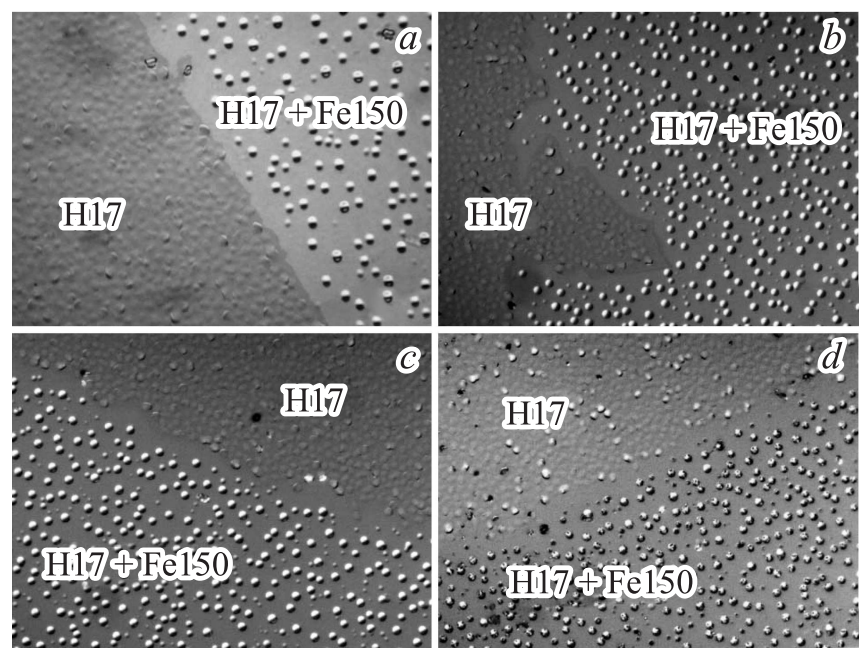

Рис. 4. Блистерная структура в областях кремния, облученных только ионами $\mathrm{H} \mathrm{c} E=17 \mathrm{keV}$ дозой $1 \cdot 10^{17} \mathrm{~cm}^{-2}$, а также последовательно ионами $\mathrm{H} \mathrm{c} E=17 \mathrm{keV}$ дозой $1 \cdot 10^{17} \mathrm{~cm}^{-2}$ и ионами $\mathrm{Fe}$ c $E=150 \mathrm{keV}$ дозой $4.9 \cdot 10^{14} \mathrm{~cm}^{-2}$, в результате получасовых изохронных отжигов при температурах $400(a)$, $600(b), 700(c)$ и $900^{\circ} \mathrm{C}(d)$.

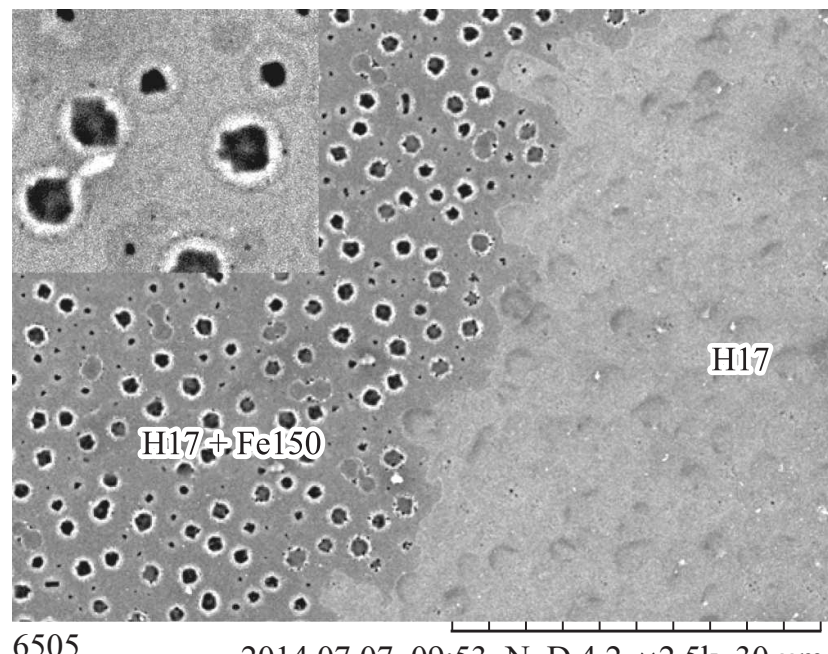

$65052014.07 .0709: 53$ N D $4.2 \times 2.5 \mathrm{k} 30 \mu \mathrm{m}$

Рис. 5. РЭМ изображение блистерной структуры в областях кремния, облученных только ионами $\mathrm{H}$ с $E=1 \mathrm{keV}$ дозой $1 \cdot 10^{17} \mathrm{~cm}^{-2}$, а также последовательно ионами $\mathrm{H} \mathrm{c}$ $E=17 \mathrm{keV}$ дозой $1 \cdot 10^{17} \mathrm{~cm}^{-2}$ и ионами $\mathrm{Fe}$ с $E=150 \mathrm{keV}$ дозой $4.9 \cdot 10^{14} \mathrm{~cm}^{-2}$, в результате получасового отжига при температуре $900^{\circ} \mathrm{C}$. На вставке при большем увеличении показано сохранение сферической формы крышек блистеров с кристаллографическим скалыванием в области образца, облученного ионами водорода и железа.

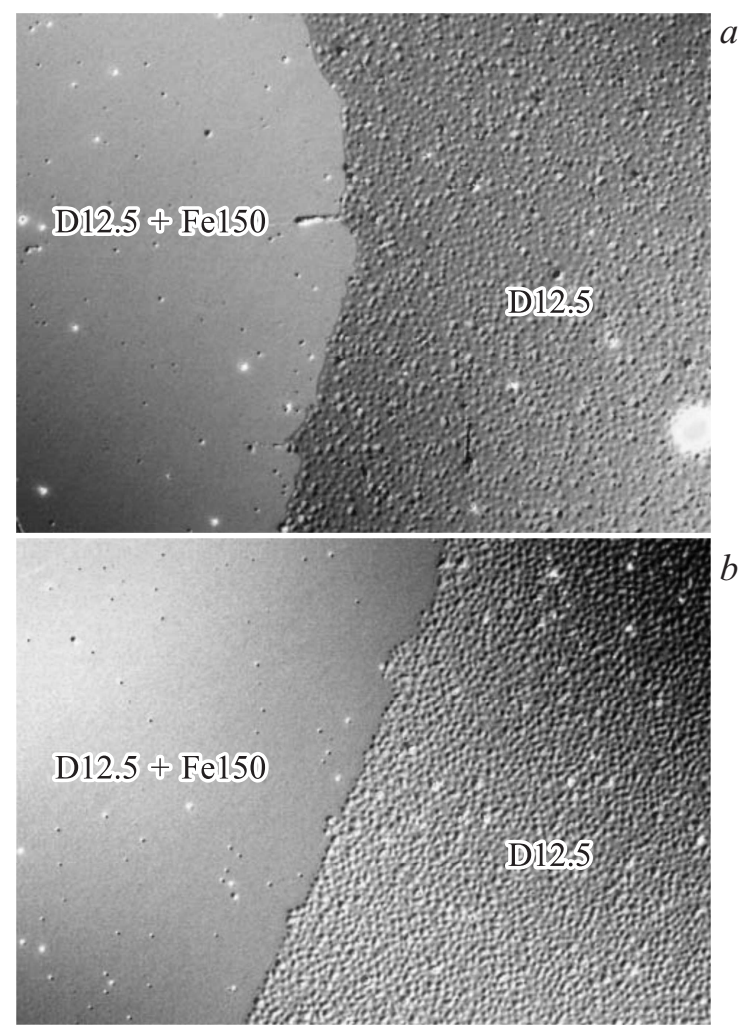

Рис. 6. Структура участков образца кремния, облученных только ионами дейтерия (D12.5 keV/1 $10^{17} \mathrm{~cm}^{-2}$ - поле c блистерами и флэкингами) и последовательно облученных ионами дейтерия и железа $\left(\mathrm{D} 12.5 \mathrm{keV} / 1 \cdot 10^{17} \mathrm{~cm}^{-2}+\right.$ $+\mathrm{Fe} 150 \mathrm{keV} / 5.9 \cdot 10^{14} \mathrm{~cm}^{-2}$ - чистое поле), после получасового отжига при $500(a)$ и $800^{\circ} \mathrm{C}(b)$. 


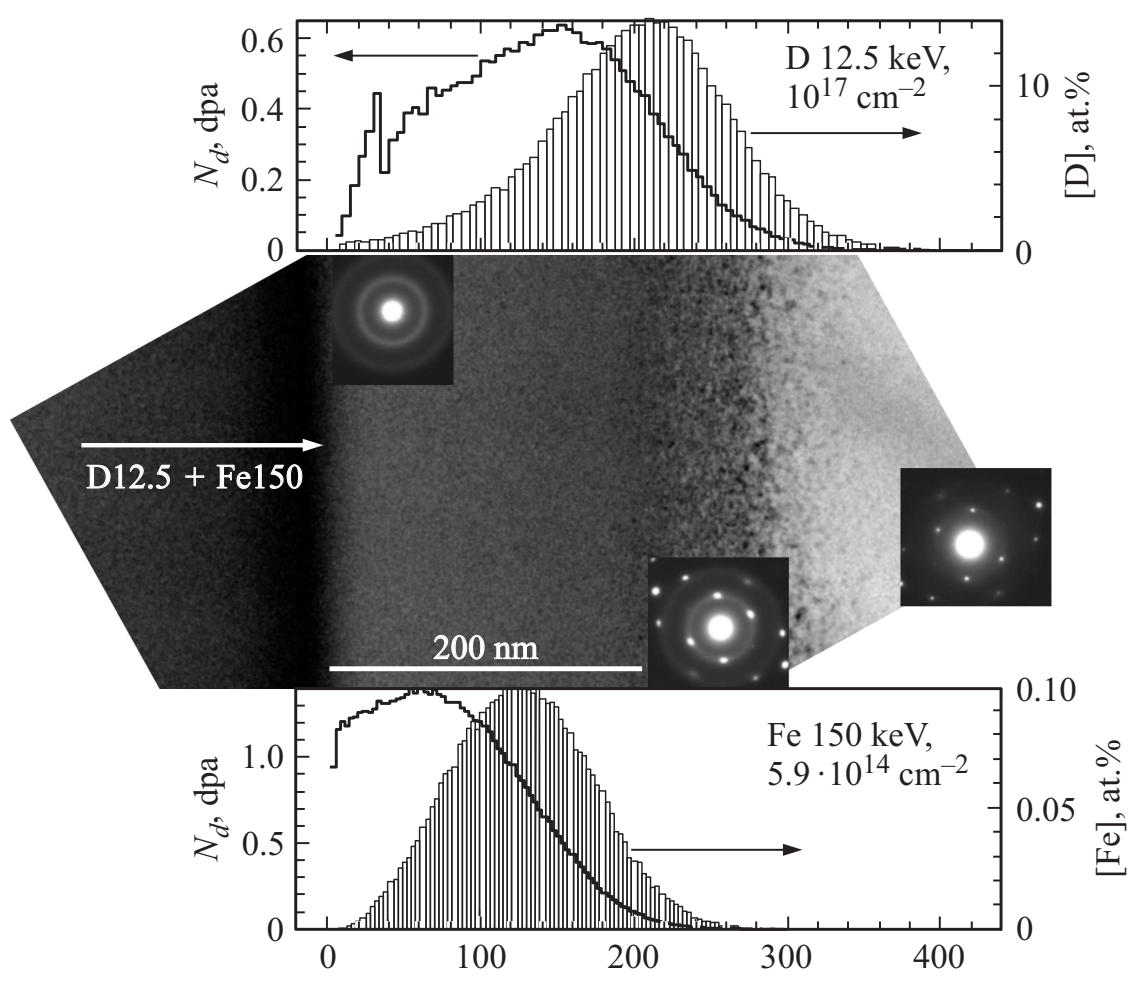

Рис. 7. ПЭМ изображение в геометрии „сcoss-section“ структурных изменений в кремнии вдоль пробега ионов после последовательного облучения ионами D c $E=12.5 \mathrm{keV}$ и ионами Fe c $E=150 \mathrm{keV}$. На вставках приведены электронограммы структурного состояния соответствующих участков радиационно поврежденного слоя кремния.

Можно предположить, что это из-за наличия углеводородной пленки на поверхности образца, образованной во время облучения ионами водорода. В областях образца, легированных водородом и дополнительно облученных ионами железа, блистеры имеют обычную полусферическую форму с нормальным контрастом их изображения в оптическом микроскопе в режиме Номарского. Предполагается, что в процессе облучения ионами железа углеводородная пленка была удалена за счет ее ионного распыления тяжелыми ионами.

Изохронные отжиги в интервале от 400 до $900^{\circ} \mathrm{C}$ практически не изменили количественные параметры блистеров в исследованных областях (рис. 4). Так, в области облучения только ионами водорода средний размер блистеров составил около $2 \mu \mathrm{m}$, плотность около $1.6 \cdot 10^{7} \mathrm{~cm}^{-2}$, площадь около $50 \%$.

В областях, облученных ионами железа, средний диаметр блистеров также составил около $2 \mu \mathrm{m}$, хотя плотность и относительная площадь уменьшились практически в 2 раза, соответственно до $7 \cdot 10^{6} \mathrm{~cm}^{-2}$ и $30 \%$. При этом особо отметим, что в областях, облученных ионами железа, наблюдается бимодальное распределение блистеров по размерам: одна мода включает блистеры со средним размером около $1.2 \mu \mathrm{m}$ и плотностью около $1.7 \cdot 10^{6} \mathrm{~cm}^{-2}$, другая - со средним размером около $2 \mu$ т и плотностью около $7 \cdot 10^{6} \mathrm{~cm}^{-2}$. Подобный характер бимодального распределения блистеров по размерам наблюдался нами и в случае кремния, облученного ионами гелия и железа, предположительно связанного с их зарождением на разных глубинах образца, возможно, по границам эпитаксиальной рекристаллизации аморфного слоя.

Кроме того, отжиги вплоть до $700^{\circ} \mathrm{C}$ не вызвали каких-либо заметных структурных изменений в пространственном распределении и морфологии блистеров как в областях, легированных только водородом, так и в областях, дополнительно облученных ионами железа. Лишь при температурах более $700^{\circ} \mathrm{C}$ (рис. 4, $d$ ) в областях, легированных водородом, наблюдается появление небольшого количества флэкингов, в то время как в областях, облученных ионами железа, практически все блистеры проявили необычный контраст в своем изображении. Как показали исследования данной области образца в растровом электронном микроскопе, все без исключения блистеры, сохранив свою полусферическую форму, имели хрупкий скол в верхней части крышек блистеров (рис. 5, вставка). Заметим, что в областях, облученных ионами водорода, только малая доля из наблюдаемых блистеров претерпела разрушение.

Итак, обобщая некоторые характерные отличительные особенности влияния на развитие водородных блистеров дополнительного облучения ионами железа, можно выделить следующие особенности:

- несмотря на одновременное зарождение блистеров при $400^{\circ} \mathrm{C}$, имеет место практически двукратное замедление процесса образования центров зарождения блистеров с их бимодальным распределением по размерам; 
- на начальных стадиях образования блистеров их полусферическая форма обусловлена, по-видимому, пластической деформацией материала крышки за счет внутреннего давления водорода в блистере, поскольку их полусферическая форма сохраняется при всех температурах отжига даже после десорбции из них водорода;

- хрупкое частичное разрушение полусферических крышек блистеров при высоких температурах возможно за счет релаксации в них напряженного состояния при рекристаллизации аморфного состояния.

\section{Дейтериевые блистеры}

Изохронные получасовые отжиги через интервал $50^{\circ} \mathrm{C}$ в диапазоне температур от 250 до $450^{\circ} \mathrm{C}$ не показали сколько-нибудь заметных структурных изменений в областях образца кремния, как легированных только атомами дейтерия, так и дополнительно облученных ионами железа. Изменения структуры в виде появления на поверхности дейтериевых блистеров имеют место после отжига при $500^{\circ} \mathrm{C}$ и только в областях, облученных ионами дейтерия (рис. 6). При этом количественные параметры наблюдаемых дейтериевых блистеров не изменялись при последующих отжигах вплоть до $800^{\circ} \mathrm{C}$ (рис. $\left.6, b\right)$. Так, средний диаметр блистеров составил $1.2 \mu \mathrm{m}$, а плотность и относительная площадь соответственно $1.5 \cdot 10^{7} \mathrm{~cm}^{-2}$ и около $30 \%$. Особо отметим, что в областях, облученных последовательно ионами дейтерия и железа, образование дейтериевых блистеров практически не наблюдалось вплоть до температуры $800^{\circ} \mathrm{C}$ (рис. $\left.6, b\right)$.

Таким образом, в отличие от гелиевых и водородных блистеров, дополнительное облучение ионами железа практически полностью подавляет образование дейтериевых блистеров. В настоящий момент трудно сказать о причинах такого влияния дополнительного облучения ионами железа на развитие дейтериевых блистеров. Предварительные ПЭМ исследования структуры в геометрии „cross section“ образца кремния непосредственно после облучения ионами дейтерия и железа показали полную аморфизацию области легирования дейтерием и отсутствие образования в ней газовых нанопор (рис. 7). В этой связи есть основание предполагать о проблемах зарождения и роста дейтериевых блистеров в аморфной матрице в процессе последующих послерадиационных температурных воздействий.

\section{Заключение}

В настоящей работе в рамках решения проблемы радиационно-газового скалывания нанометрических монокристаллических слоев кремния получены результаты влияния аморфного слоя в кремнии, сформированного дополнительным облучением ионами железа, на развитие гелиевых, водородных и дейтериевых блистеров.

Необычным и неожиданным явились результаты крайне различного влияния последующего облучения ионами железа образцов, предварительно облученных ионами газов, на развитие газовых блистеров в кремнии: от явно стимулированного развития гелиевых блистеров до некоторого уменьшения развития водородных блистеров вплоть до полного подавления развития дейтериевых блистеров.

Полученные результаты не позволяют в настоящий момент сформулировать сколько-нибудь адекватного объяснения причин такого различия, необходимы целенаправленные эксперименты. Тем не менее на лицо сильный синергетический эффект влияния последовательного облучения ионами газов и ионами железа образцов монокристаллического кремния при комнатной температуре на зарождение и рост газовой пористости в процессе послерадиационного отжига.

\section{Список литературы}

[1] Балагуров Л.А. // Материаловедение. 1998. Вып. 1. С. 5056.

[2] Балагуров Л.А. // Материаловедение. 1998. Вып. 3. С. 23 45.

[3] Кашкаров П.К. // Соросовский образовательный журнал. 2001. № 1. C. 102-107.

[4] Primak W., Dayal Y., Edwards E. // J. Appl. Phys. 1963. Vol. 34. P. 827.

[5] А.c. № 1282757.3012. Способы изготовления тонких пластин кремния / В.Ф. Реутов, Ш.Ш. Ибрагимов. 1983.

[6] Patent USA. N 5374564 . Process for the production of thin semiconductor material films / M. Bruel. 1995.

[7] Bruel M. // Electron. Lett. 1995. Vol. 14. P. 1201-1202.

[8] Henley F., Lamm A., Kang S., Liu Z, Tiam L. // Proc. of the $23^{\text {rd }}$ European Photovoltaic Solar Energy Conf. München, 2008. P. 1090.

[9] Myers S.M., Follstaedt D.M., Bishop D.M. // MRS Symp.Proc. 1994. Vol. 316. P. 53.

[10] Myers S.M., Bishop D.M., Follstaedt D.M., Stein H.J., Wampler W.R. // MRS Symp. Proc. 1993. Vol. 283. P. 549.

[11] Huang L.J., Tong Q.Y., Chao Y.I., Lee T.H., Martini T., Gosele U. // Appl. Phys. Lett. 1999. Vol. 74. P. 982. 